\title{
PROFESSORES DE GEOGRAFIA DO ENSINO FUNDAMENTAL II E AS LEIS FEDERAIS 10.639/2003 E 11.645/2008
}

\author{
Aluê Gomes da Silva \\ LAGEPOP-IG-Universidade Federal de Uberlândia - UFU. \\ E-mail: aluegomes@yahoo.com.br \\ Adriany de Ávila Melo Sampaio \\ LAGEPOP-IG- Universidade Federal de Uberlândia - UFU. \\ E-mail: adrianyavila@gmail.com
}

\begin{abstract}
RESUMO
Este trabalho tem como objetivo analisar como os professores de Geografia do Ensino Fundamental II aplica as leis federais 10.639/2003 e 11.645/2008 em sala de aula. Estas leis incluíram oficial no currículo oficial da Rede de Ensino a obrigatoriedade da temática "Histórias e Culturas Afro-Brasileiras e Indígenas". O estudo terá caráter qualitativo, com ênfase na Análise de conteúdo das respostas dos professores de Geografia do Ensino Fundamental II de escolas públicas da cidade de Uberlândia, Minas Gerais, que participaram da pesquisa. As leis federais 10.639/03 e 11.645/08 se propõe a refletir, atribui à discussão e reflexão acerca da história, da memória e da luta dos povos negros e indígenas socialmente excluídos ao longo do processo histórico do Brasil, até os dias atuais. De modo geral percebe-se que os professores têm avançado em relação às leis, como também o interesse de trabalhar com a temática, por isso a necessidade de formação de professores para aproximação e desmitificação para com os conhecimentos da cultura indígena, africana e afro brasileira. Construir uma identidade positiva e de afirmação social do indígena e do negro é necessário. A escola deve se apropriar de estratégias educativas de combate às formas de discriminação étnica, inicialmente a partir de uma formação dos profissionais da educação, e inclui-los nas ações pedagógicas que forneçam aos alunos a oportunidade de valorizar, conhecer, vivenciar a cultura negra e indígena. A Geografia a partir de suas categorias como lugar, paisagem, território e região, tem condições de realizar uma docência antirracista, mas para isso são necessários a formação inicial e continuada, e também de livros e outros materiais didáticos na mesma perspectiva.
\end{abstract}

Palavras chaves: Lei 10.639/03 e 11.645/08. Pesquisa. Ensino de Geografia, Racismo.

\section{INTRODUÇÃO}

Este estudo busca analisar respostas dos professores de Geografia da Educação Básica, Ensino Fundamental II ao que se refere as Leis 10.639/2003 e 11.645/2008. De modo geral percebe-se que os professores têm avançado em relação às leis, como também no interesse de trabalhar com a temática, por isso a necessidade de formação de professores para aproximação e desmitificação para com os conhecimentos da cultura indígena, africana e afro brasileira.

A sociedade brasileira ainda exige que existam leis referentes ao ensino da história e culturas Afro-Brasileiras e Indígenas e carece de sua aplicabilidade, caso contrário muitas não serão colocadas em ação. Por exemplo: as leis 10.639/2003 e 11.645/2008 ainda não são empregadas nas escolas. 
Uma das hipóteses sobre essa questão é que os professores não entendem a importância da temática cultura indígena africana e afro-brasileira no currículo fica nítida a necessidade da formação de professores, tanto inicial quanto de forma continuada, especialmente dos professores de Geografia que é a disciplina que discute a formação social e territorial do Brasil.

Torna-se necessária uma revisão de forma mais assertiva as questões relativas ao ensino da história e cultura afro-afro-brasileira e indígena para que os professores sejam instruídos "não só a compreender a importância das questões relacionadas à diversidade étnica, mas a lidar positivamente com ela e, sobretudo, criar estratégias pedagógicas que possa auxiliar e reeduca-las" (BRASIL, 2004, p.17).

Construir uma identidade positiva e de afirmação social do indígena e do negro é necessário. A escola deve se apropriar de estratégias educativas de combate às formas de discriminação étnica, inicialmente a partir de uma formação dos profissionais da educação, e inclui-los nas ações pedagógicas que forneçam aos alunos a oportunidade de valorizar, conhecer, vivenciar a cultura negra e indígena.

A Geografia a partir de suas categorias como lugar, paisagem, território e região, tem condições de realizar uma docência antirracista, mas para isso são necessários a formação inicial e continuada, e também de livros e outros materiais didáticos na mesma perspectiva. Lembrar das leis federais 10.639/2003 e 11.645/2008 somente em datas comemorativas não é suficiente. A disciplina de Geografia é abrangente o suficiente para relatar processos sociais e históricos de lutas para reconhecimento desses povos em diversos momentos do ensino em sala de aula.

Entende-se que as leis devem e podem ser implementadas por todos os componentes curriculares e a disciplina de Geografia que estuda a relação recíproca entre o homem e o meio pode desempenhar papel fundamental ao proporcionar discussões sobre os processos de construção cotidiana e histórica, no que se refere às contribuições das manifestações da cultura indígena, afro-brasileira e africana na constituição do Brasil.

\section{ENSINO DE GEOGRAFIA DO ENSINO FUNDAMENTAL II E A LEI FEDERAL 10.639/2003 E 11.645/2008.}

As Leis 10.639/2003 e 11.645/08 representam uma conquista aos instrumentos de luta e de contestação a todo tipo de preconceito racial, no âmbito da educação formal. As Diretrizes Curriculares Nacionais para a Educação das Relações Étnico- 
Raciais e para o Ensino de História e Cultura Afro-Brasileira e Africana preconizam a construção da educação sob os signos do reconhecimento da diferença étnico-racial e da igualdade de direito.

A lei $\mathrm{n}^{\mathrm{o}}$ 10.639, de 9 de janeiro de 2003. Altera a Lei no 9.394, de 20 de dezembro de 1996, que estabelece as diretrizes e bases da educação nacional, para incluir no currículo oficial da Rede de Ensino a obrigatoriedade da temática "História e Cultura Afro-Brasileira", e dá outras providências.

\begin{abstract}
Art. 1o A Lei no 9.394, de 20 de dezembro de 1996, passa a vigorar acrescida dos seguintes arts. 26-A, 79-A e 79-B: "Art. 26-A. Nos estabelecimentos de ensino fundamental e médio, oficiais e particulares, torna-se obrigatório o ensino sobre História e Cultura Afro-Brasileira.

$\S 1$ o O conteúdo programático a que se refere o caput deste artigo incluirá o estudo da História da África e dos Africanos, a luta dos negros no Brasil, a cultura negra brasileira e o negro na formação da sociedade nacional, resgatando a contribuição do povo negro nas áreas social, econômica e política pertinentes à História do Brasil.

§ 20 Os conteúdos referentes à História e Cultura Afro-Brasileira serão ministrados no âmbito de todo o currículo escolar, em especial nas áreas de Educação Artística e de Literatura e História Brasileiras. (BRASIL, 2003).
\end{abstract}

A lei $n^{\circ}$ 11.645, DE 10 MARÇO DE 2008. Altera a Lei no 9.394, de 20 de dezembro de 1996, modificada pela Lei no 10.639, de 9 de janeiro de 2003, que estabelece as diretrizes e bases da educação nacional, para incluir no currículo oficial da rede de ensino a obrigatoriedade da temática "História e Cultura Afro-Brasileira e Indígena".

\footnotetext{
"Art. 26-A. Nos estabelecimentos de ensino fundamental e de ensino médio, públicos e privados, torna-se obrigatório o estudo da história e cultura afrobrasileira e indígena.

$\S 1^{\circ} \mathrm{O}$ conteúdo programático a que se refere este artigo incluirá diversos aspectos da história e da cultura que caracterizam a formação da população brasileira, a partir desses dois grupos étnicos, tais como o estudo da história da África e dos africanos, a luta dos negros e dos povos indígenas no Brasil, a cultura negra e indígena brasileira e o negro e o índio na formação da sociedade nacional, resgatando as suas contribuições nas áreas social, econômica e política, pertinentes à história do Brasil.

$\S 2^{\circ}$ Os conteúdos referentes à história e cultura afro-brasileira e dos povos indígenas brasileiros serão ministrados no âmbito de todo o currículo escolar, em especial nas áreas de educação artística e de literatura e história brasileiras." (BRASIL, 2008).
}

Assim conforme a questão proposta nas Diretrizes Curriculares Nacionais para o Ensino da Educação das Relações Étnico- Raciais e para o Ensino de História e Cultura Afro-Brasileira e Africana, no que diz respeito à mudança do discurso, sua implicação na prática do professor requer o manejo do programa e da matriz curricular. 
Silva (1999) afirma que o currículo não é uma construção neutra, mas resultado de diversos interesses políticos e econômicos de grupo sociais que naturalizam o processo das relações sociais para manter a ordem, como também a rotina de trabalho do professor bem como as suas escolhas individuais com base nos seus conhecimentos técnicos e suas escolhas ideológicas que se encontram de forma explicita ou não na organização, no planejamento, no plano de curso, nos objetivos da aula, nas atividades desenvolvidas e nas avaliações.

[Lei 10.639/2003] Tal texto é resultado de um complexo processo de construção. Sendo conquista de lutas de movimentos sociais há décadas, que são traduzidas e debatidas pelo Congresso Nacional e pelo Poder Executivo Federal (antes, elas já haviam sido "traduzidas" em legislações municipais e estaduais de teor semelhante), este texto é, na verdade, síntese e simplificações da ampla pauta das lutas daquelas que conquistaram a Lei. Com efeito, ao longo de décadas as lutas educativas do Movimento Negro tiveram pautas muito mais abrangentes, mas a relação com Estado e o processo legislativo resultaram neste texto. (SANTOS, 2011, p. 6)

O autor revela que a lei, em seus principais pontos, é um complexo de resultados de construção do movimento negro. O currículo é central para o aprendizado da Geografia abrangendo também o livro didático praticado como forma de aprendizado no ensino de Geografia, abrangendo também os livros didáticos que são inseridos e indicados nas escolas. Um currículo adequado deveria dizimar as distorções e também divergências.

Santos (2011) também expõe que os conceitos apresentados no currículo, de forma geral, sobre a raça negra estão deturpados, pois promovem a depreciação e exclusão do negro para uma maior parte da população, quanto a sua origem e quanto a sua vivência em sociedade, ou seja, reforça a discriminação pela cor da pele e não valoriza sua ancestralidade.

$\mathrm{Na}$ perspectiva de romper com tais relações de dominação, a política educacional é compreendida pelos autores como uma política social, que busca a garantia dos direitos dos sujeitos por meio da ação do Estado. A partir disso, é possível compreender que as leis $\mathrm{n}^{\circ} 10.639 / 2003$ e $11.6345 / 2008$ configuram- se como medidas ainda mais incisivas de fazer com que a política educacional se torne política social para a garantia da justiça e dos direitos humanos, por que preconizam que todos os sujeitos tenham direito à diferença e ao conhecimento da própria epistemologia, compreendendo de maneira crítica as razões pelas quais o preconceito racial se justificou historicamente neste país". (LIMA e REGO, 2017, p. 179). 
As autoras dizem que a política pública brasileira que deveria ser igualitária para todos, privilegia a brancura e valoriza principalmente as raízes europeias da sua cultura, ignorando ou pouco valorizando as outras que são indígenas e africana. Como também as várias manifestações de violência étnico-racial se revela no acesso da população negra à justiça e informa que a democracia está necessariamente relacionada ao acesso aos direitos humanos. Ainda acontece o silenciamento territorial, étnico, político e epistemológico, pois as contribuições indígenas, africanas e afro-brasileiras não são reconhecidas como produção de conhecimento e cultura.

Por isso visando compreender a escola numa ação conjunta, raça, currículo e práxis pedagógicas, o parecer 3/2004 (BRASIL, 2006) das Diretrizes Curriculares Nacionais para o Ensino da Educação das Relações Étnico-Raciais e para o Ensino de História e Cultura Afro-Brasileira e Africana, tem como fim subsidiar a escola, o professor e todos aqueles que prezam uma educação do reconhecimento e da diferença étnico- racial para o exercício da democracia.

Oliveira e Silva (2017) discutem a lei 10.639/2003 e evidenciam que há regulamentação sobre a hegemonia do conhecimento eurocêntrico e socialmente valorizados pela secular elite brasileira nos currículos escolares. Os autores discutem que ao tomarmos o ensino da cultura, da arte e da literatura africana e afrodescendente como objeto de pesquisa no contexto da formação inicial de professores, buscamos contribuir para a ressignificação de aspectos relevantes da identidade da população brasileira. Sendo assim o caráter sócio-político sem seu comprometimento com o desvendar de fatos, que o racismo estrutural estabelece impedem a efetivação de uma sociedade inclusiva e democrática. O texto busca perceber ideologias, crenças e representações sociais sobre a educação étnico- racial que constituem os discursos dos futuros professores da educação básica.

Silva (2007, p. 500) relata que:

As dificuldades para implantação dessas políticas curriculares assim como a estabelecida no art. $26^{\circ}$ da Lei 9.394/1996, por força da Lei 10.639/2003, se devem muito mais à história das relações étnico raciais neste país e aos processos educativos que elas desencadeiam, consolidando preconceitos e estereótipos, do que a procedimentos pedagógicos, ou à tão reclamada falta de textos e materiais didáticos. Estes, hoje, já não tão escassos, mas nem sempre facilmente acessíveis, no entanto, não há como desconhecer experiências desenvolvidas por professores negros e não negros, na sua grande maioria contando com o apoio do Movimento Negro e que com certeza proporcionara apoio para a formulação do Parecer CNE/CP 3/2004, bem como serviram de exemplo e suporte para que se execute esta determinação legal. 
O ato de aplicar a lei no ambiente escolar requer dos professores uma atitude não omissa, não inferiorizar a diversidade étnico racial, admitindo que a sociedade brasileira é racista. No Brasil, o racismo é ocultado por parte da sociedade que exclui os diferentes, sendo eles, índios ou afrodescendentes, dando uma ideia de não pertencimento, pois a sociedade que diz integrar é a mesma que exclui.

Com legislação contra o racismo o estado brasileiro é obrigado a valorizar a diversidade, o que torna o racismo um crime inafiançável e imprescritível, garantindo a cultura própria e o reconhecimento das contribuições negras e indígenas.

\section{CONSIDERAÇÕES FINAIS}

Sobre os objetivos das leis federais 10.639/2003 e 11.645/2008, a maioria dos professores se expressou de forma geral, sendo que muitas das respostas se assemelhavam em conteúdo superficial sobre a questão. De certa forma, não foi possível ter certeza de que os professores pesquisados realmente conheciam as leis em foco. Esperava-se aqui que os professores tivessem respondido o que realmente sabiam, ou entendiam, sem preocupação de respostas certas ou erradas. Assim, considerando as respostas coletadas pode-se afirmar que todos já ouviram falar das leis, mas não mostraram entendimento profundo do que os objetivos delas significam para o dia a dia da escola.

Em relação à informação sobre as leis 10.639/2003 e 11.645/2008 durante a formação docente, apenas três professores receberam, sendo que quatro passaram pela graduação sem nenhum conhecimento sobre o assunto. Pode-se afirmar que $60 \%$ dos professores não tiveram formação a respeito, o que evidencia uma realidade encontrada nas escolas.

\section{REFERÊNCIAS}

BRASIL. Casa Civil, Lei n⿳10.639, de 9 de janeiro de 2003. Brasília, DF.

BRASIL. Constituição da República Federativa do Brasil: Lei 11.645, de 10 de Março de 2008.

BRASIL. Diretrizes Curriculares para a Educação das Relações Étnico-Raciais e para o Ensino de História e Cultura Afro-Brasileira e Africana, Brasília, DF, junho, 2005.

BRASIL. LDBEN 9394/96, Brasília, MEC, DF, 2009. 
BRASIL. Orientações e Ações para a Educação das Relações Étnico- Raciais. Ministério da Educação, Secretaria da Educação Continuada, Alfabetização e Diversidade. Brasília: SECAD, 2006.

CHAGAS, Anivaldo Tadeu Roston. $\mathrm{O}$ questionário na pesquisa cientifica. Administração online, São Paulo, v.1, n. 1, jan./ fev./mar. 2000

CUNHA JUNIOR, J. et al. Artefatos da cultura negra no Ceará: formação de professores: 10 anos da Lei n॰ 10639/2013. In: cadernos de textos. Fortaleza: Gráfica LCR; 2013. p. 11-22.

HASENBALG, Carlos Alfredo. Discriminação e Desigualdades Raciais no Brasil. Rio de Janeiro, Edições Graal, 1992.

LIMA, D. C. B. P.; REGO, T. L. Educação das relações étnico-raciais na educação infantil. In: Revista contemporânea de educação, v. 12, p. 175-191, 2017.

NASCIMENTO, Alexandre do. Ação Afirmativa: da luta do movimento social negro às políticas concretas. Rio de Janeiro: CEAP, 2006.

OLIVEIRA, M. G; SILVA, P. V. B. Educação Étnico- Racial e Formação Inicial de Professores: a recepção da Lei 10.639/03. In: Educação e realidade, v. 42, p. 183- 196, 2017.

PEREIRA, G. R; CORDEIRO, M. J. A. A diversidade das relações étnico-raciais e o currículo escolar: algumas reflexões. In: Interfaces da educação. Parnaíba, v.5. n.14, p7-22, 2014.

SANTOS, Renato Emerson Nascimento dos. A Lei 10.639 e o ensino de geografia: construindo uma agenda de pesquisa- ação. In: Revista Tamoios, v.7, p. 4-23, 2011.

SILVA, P. B. G. e. Aprender, ensinar e relações étnico-raciais no Brasil. In: Educação, Porto Alegre/RS, n. 3 (63), p. 489-506, set./dez. 2007.

SOUZA, Maria Helena. A Ideologia Racial Brasileira na Educação Escolar. In. OLIVEIRA, Iolanda e SISS, Ahyas (Orgs.). Cadernos PENESB, No 7, Niterói, RJ, EdUFF, 2006. 